\title{
Cidadania, participação social e mobilização política
}

\author{
Citizenship, social participation \\ and political mobilization
}

Manuel Villaverde Cabral [l]

\section{Resumo}

Na primeira parte deste texto, debruço-me sobre as noções de cidadania e de sociedade civil, procurando mostrar de que forma elas evoluíram historicamente uma em relação à outra. A seguir, mostro de que forma um novo tipo de contrato social - 0 chamado welfare state - surgiu nos países demo-liberais após a crise de 1929 e a Segunda Guerra Mundial. No termo dessa reflexão, identificarei a noção de capital social como veículo privilegiado dos processos sociais de inclusão versus exclusão. Por fim, apresentarei os resultados de um inquérito internacional que permite identificar as características comparativas dos modernos processos de associativismo, mobilização e mudança sociocultural.

Palavras-chave: cidadania; sociedade civil; capital social; associativismo; mobilização política.

\begin{abstract}
First, I will discuss the notions of citizenship and civil society in order to show their historical evolution in relation to each other. Second, I will show the way in which a new type of social contract - the so-called Welfare State - will emerge in the demo-liberal countries after the 1929 crisis and the 2nd World War. Then, I will identify the notion of social capital as a privileged vehicle of the social processes of inclusion versus exclusion. Finally, I will present the results of an international survey that allows to identify comparative characteristics present in modern processes of association, mobilization, and socio-cultural change.
\end{abstract}

Keywords: citizenship; civil society; social capital; association; political mobilization. 


\section{Cidadania e sociedade civil}

Sociedade civil e cidadania remetem, de algum modo, uma para a outra, sendo difícil dizer qual precede ou qual pressupõe a outra. Em todo caso, pode dizer-se que a sociedade civil - isto é, a organização de redes e grupos autónomos de defesa de valores e interesses distintos ou concorrentes entre si, e sobretudo distintos das esferas de interesse do Estado e das igrejas constitui a materialização efectiva do exercício da cidadania. Contudo, se a noção de sociedade civil só faz sentido com a formação do Estado moderno no século XVII, ela pode emergir antes mesmo do reconhecimento dos direitos políticos e da sua institucionalização sob os regimes liberais, ao longo de um processo lento e tudo menos linear, cheio de avanços e recuos da franquia eleitoral individual, percurso este que, em Portugal, apenas se universalizou de forma genuína com o 25 de abril de 1974, fazendo então coincidir cidadania e sociedade civil num mesmo espaço estadual nacional.

A noção de cidadania parece, no entanto, ser anterior à de sociedade civil e remeter para a emergência dos direitos pessoais e corporativos que os habitantes de algumas cidades medievais, os chamados "burgueses", incluindo em países como Portugal medieval, foram adquirindo através de determinados tipos de forais, como na Lisboa do final do século XIV. 0 ponto é que a cidadania nasce territorializada, circunscrita primeiro às cidades e às suas áreas de influência, tipicamente na Itália renascentista, e ainda hoje é possível observar um efeito metropolitano positivo sobre o exercício activo da participação cívica e da mobilização política (Cabral, 2008a), como se, para usar uma expressão recuperada por Max Weber, o ar da cidade trouxesse, efectivamente, um espírito de liberdade (Weber, 1958[1921]). Só depois a cidadania se foi estendendo, mitigadamente, aos chamados Estados-Nação, sob a forma daquilo a que damos, correntemente, o nome de nacionalidade, mas que os anglo-saxónicos designam precisamente por citizenship, mantendo, assim, a ligação entre cidadania e território.

A nacionalidade, nos poucos territórios onde de início ela se vai manifestando, e Portugal é um deles, começa na realidade por ser o direito de protecção interna e externa de pessoas e bens, correlativo da entrega, por assim dizer, da soberania ao Estado, segundo o esquema hobbesiano de troca, digamos assim, de soberania por segurança. Nesse sentido, a nacionalidade garantida pelos Estados absolutistas, originariamente no século XVII e prolongando-se pelo XVIII e em boa parte do XIX, reabsorveu a sociedade civil embrionária das cidades medievais e renascentistas.

Já a nacionalidade enquanto cidadania - isto é, o conjunto de direitos civis, políticos, sociais e culturais - é algo muito mais tardio, identificado apenas a seguir à Segunda Guerra Mundial por Thomas Herbert Marshall, num ensaio luminoso de 1950 sobre cidadania e classes sociais, que tem constituído, desde então, a bíblia da inclusão social (Marshall, 1992). Marshall estava, na realidade, a teorizar o início do contrato social keynesiano que configurava, para as décadas seguintes, o modelo do welfare state, adoptado mutatis mutandis nas democracias europeias, com muitas diferenças já também teorizadas (Esping-Andersen, 1990), enquanto contrapartida material ou, se preferirmos, enquanto substanciação dos direitos conferidos à cidadania cívica e política pela democracia. 
Esses novos direitos sociais, aos quais a sociedade portuguesa ascenderia, a sua modo, com o 25 de abril e de então para cá, correspondem, à maneira de Keynes (1936), ${ }^{1}$ à necessidade de sustentar a procura solvável das famílias nas três situações em que, identificadamente, os membros da população activa, os trabalhadores, não estão em condições de trabalhar e, portanto, de angariar recursos próprios: o desemprego, a velhice e a doença. Com a evolução do impropriamente chamado "estado-providência" - já que o Estado nada providencia, nós é que providenciamos os nossos impostos ao Estado -, a inclusão económica e a coesão social foram sendo assumidas pelos seus dois pilares estatais: a segurança social e o sistema público de saúde, aos quais se associaram, em nome da produção de "capital humano", a educação pública e a habitação social. Eis o ponto em que o desenvolvimento histórico da noção de cidadania nos faz chegar ao domínio da inclusão e da exclusão sociais, que abordarei daqui a um instante.

Entretanto, sem pretender fazer a narrativa exaustiva de um longo e complexo processo, convém recordar que o conceito propriamente dito de sociedade civil emerge, como havia dito, no século XVIII, na Escócia, com o filósofo Adam Ferguson, que vai escrever, em 1767, o primeiro "ensaio sobre história da sociedade civil", enquanto manifestação dos novos interesses mercantis e industriais, mas também de secessão religiosa e intelectual, por diferenciação relativamente à ordem estatal aristocrática e fundiária, então vigente. Ao amadurecer, o conceito evoluiu no sentido de uma esfera cívica diferenciada, embora nunca radicalmente autónoma do Estado, do mercado e das igrejas, assim como da própria esfera familiar e privada.
Na Alemanha, contudo, o conceito é sintomaticamente designado por Bürgerliche Gesellschaft, ou seja, a "sociedade burguesa", em suma, as "forças vivas" do burgo, conferindo assim à noção de sociedade civil o significado de uma esfera de interesses económicos privados, autónomos e, no limite, em competição com o Estado-Nação em nascimento, se não mesmo opostos às instituições públicas. Para alguém como Hegel, que aspirava à formação de um Estado alemão, a vigilância reguladora estatal sobre a sociedade burguesa era absolutamente necessária para corrigir, por assim dizer, a sua livre actuação.

Mais tarde, inspirado pela sua visão da democracia norte-americana, Alexis de Tocqueville foi praticamente o último grande defensor da ideia de sociedade civil enquanto contrapeso, simultâneo, ao individualismo liberal e ao centralismo estatal. Contudo, numa espécie de síntese actualizada dessa controvérsia política, o filósofo norte-americano John Rawls acabaria por designá-la como "sociedade organizada", organized society, na sua grande teoria sobre a equidade social no século $\mathrm{XX}$. $\mathrm{Na}$ mesma linha que Hegel, também Rawls considera que é função do Estado, precisamente, defender o interesse público contra eventuais vantagens adquiridas pelos interesses mais bem organizados e mais influentes (Rawls, 1972). Essa dimensão realista da chamada sociedade civil, implícita na teoria de Rawls, voltará a surgir com força na última década do século $X X$, quando os temas articulados da sociedade civil e do exercício da cidadania reemergem, após um longo período de silêncio, com o início da globalização e o retorno ao liberalismo económico no início da década de 70 do século passado. 
A partir do momento em que essas tendências se conjugam, nos anos 1990, com a implosão do chamado "socialismo real", abre-se o espaço à emergência daquilo a que Jeffrey Alexander chamou as "sociedades civis reais" (Alexander, 1998). Simultaneamente, generalizam-se apelos à "libertação da sociedade civil" adversos ao Estado centralista e burocrático que tal "libertação" desafiava. Foi, pois, nesse contexto que tais conceitos ganharam actualidade e impacto na renovação da teoria democrática, nomeadamente com a investigação do cientista político norte-americano Robert Putnam sobre a descentralização político-administrativa em Itália (Putnam, 1993).

Com efeito, a forma regionalmente diferenciada como esse processo ocorreu permitiu a Putnam dar-se conta de que o potencial democratizador da devolução de direitos e deveres às regiões italianas era tanto melhor utilizado por estas quanto mais profundas eram as raízes históricas do exercício do associativismo profissional e empresarial, em suma, quanto mais precoces e fortes eram as sociedades civis regionais. A sua prolongada pesquisa gerou uma controvérsia que dura até hoje. Contudo, o autor mais não fazia do que redescobrir a teoria do "capital social" de James Coleman, que era, na realidade, uma teoria económica aplicada a microcomportamentos sociais (Coleman, 1990). Ao aplicá-la à escala societal, Putnam abriu o campo a uma reconciliação extremamente fértil, embora complexa, entre as noções de cidadania e sociedade civil (Cabral, 2008).

\section{Da exclusão e inclusão sociais ao "Terceiro Sector" e ao voluntariado}

A sofisticação e a diferenciação crescentes do modelo do capital social permitiram, inclusivamente, articulá-lo com a problemática da exclusão e inclusão sociais. As múltiplas ambiguidades da noção de exclusão social são reconhecidas pelo psicanalista e sociólogo francês Robert Castel, cuja obra sobre as "metamorfoses da questão social" lançou esse novo paradigma dos direitos sociais na era pós-keneysiana (Castel, 1995). Como Castel clarificou posteriormente, uma coisa é a exclusão individual explícita de pessoas cujo "elo social" se quebrou, levando à sua desfiliação relativamente à sociedade, como, por exemplo, os chamados "sem abrigo"; outra é a exclusão implícita de grupos etno-culturais identificados como "outros"; essas formas dever-se-iam menos a causas económicas, como a renda, do que a motivos psicosociais definidos.

Outra modalidade, ainda, que veio a sobrepor-se à matriz inicial de Castel é aquela que hoje designamos genericamente como exclusão social, ou seja, a incapacidade económica devida seja à marginalidade social, seja ao desemprego, à velhice ou a outros handicaps. Assim se verificou gradualmente, nos países mais desenvolvidos, a difusão de intervenções estatais permanentes, embora controladas através da verificação dos meios de subsistência, que levaram ao chamado "rendimento mínimo garantido", iniciado em França em 1988 
e que existe, também no Brasil, com o nome de Bolsa Família.

Essa verificação dos meios de subsistência dos assistidos acarreta, porém, disfunções potenciais, desde o clientelismo ao paternalismo, totalmente opostos ao carácter abstracto e universal dos direitos sociais que o contrato keneysiano supunha. Castel foi o primeiro a assinalar a ambiguidade dessas discriminações positivas através das quais os direitos sociais têm vindo a ser descontratualizados. Com a recente depressão económica mundial, tornou-se mais difícil ainda sustentar o desemprego e as baixas pensões de camadas socialmente integradas, mas com rendimentos abaixo do nível de pobreza relativo (Sen, 1983). Para descrever esse estado de vulnerabilidades e de exclusões, mais ou menos violentas, profundas e irreversíveis, Castel fala da "multiplicação de pessoas que ocupam na sociedade uma posição de supra-numerários" (Castel, 1995, p. 11).

Simultaneamente, um novo paradigma temático da ciência política acerca da qualidade da democracia ficaria a dever-se, de forma determinante, à queda do muro de Berlim e à implosão do sistema soviético. Com efeito, na medida em que a democracia eleitoral passou a estar, por assim dizer, sozinha no mercado da representação política legítima, ficou sujeita a maior escrutínio e exigência por parte dos representados e, correlativamente, dos cientistas e analistas políticos (Cabral, 2000).

0 retorno da sociedade civil e o seu desdobramento em capitais sociais de diversa natureza - uns mais inclusivos, outros mais excludentes - geraram, entretanto, um revival do associativismo e sobretudo do chamado terceiro sector, com um enorme surto de organizações não governamentais - essas
ONGs tipicamente situadas entre o Estado e o mercado, numa fronteira entre o público e o privado que nem sempre está traçada com a clareza (Salamon et al., 1999-2004). Essa falta de demarcação clara entre Estado, mercado e sociedade deu inclusivamente origem àquilo que no mundo anglo-saxónico se dá o nome de Quangos, isto é, quasi-non governmental organizations, onde a mão do Estado e a do próprio mercado estão muito próximas. Esta é uma manifestação recente daquilo que sempre foi visto, por alguns observadores, como the dark side of social capital. ${ }^{2}$

Inversamente, nada ilustra melhor o problema da rigorosa independência a manter pelas organizações da sociedade civil em relação aos poderes públicos, às organizações político-partidárias, às igrejas e até aos próprios movimentos sociais, do que a actividade desenvolvida pelas fundações e por outras instituições filantrópicas e mecenáticas. 0 sociólogo português João Freire (2008) tem um trabalho muito importante no qual resume a evolução do associativismo clássico, participativo e cooperativo, para um associativismo de prestação de serviços e de delegação de poderes, como, aliás, o próprio Putnam (2003) assinala noutro famoso livro.

\section{"Saída, voz e lealdade" 3}

Veremos, para concluir, aquilo que se pode esperar do funcionamento da democracia e do exercício da voz da cidadania. No nosso primeiro inquérito sociológico, observámos uma correlação negativa estatisticamente significativa entre o exercício activo da cidadania por parte da população portuguesa e a percepção 
que essa tinha da equidade social reinante na nossa sociedade, estimada através da percepção subjectiva daquilo que designámos, então, por equidade do sistema de oportunidades e recompensas socioeconómicas (Cabral, 1997).

$\mathrm{Na}$ altura, os inquiridos consideravam que o sistema de oportunidades era relativamente aberto; em contrapartida, o sistema de recompensas era considerado muito iníquo. Desde então, tenho-me concentrado nas mediações socioculturais subjacentes ao exercício activo da cidadania e à satisfação com a democracia. Num estudo internacional de 2004 (ver Quadro 1), pretendeu-se averiguar de que maneira se posicionavam a classe média-alta e a classe trabalhadora perante os atributos e atitudes que tipificam a participação política e a adesão à democracia. Comparei, assim, 0 conjunto das duas camadas superiores da sociedade europeia - empresários, proprietários, profissionais liberais, técnicos superiores, etc. -, que designei por elites, com o operariado, que não é, como se sabe, a classe mais pobre nem a menos organizada da nossa sociedade (Cabral, 2006).

No Quadro 1, temos em linha alguns dos mais importantes factores habitualmente associados ao exercício activo da cidadania e à satisfação com o regime representativo; em coluna, temos - para Portugal e para quatro outros países para comparação, bem como 0 conjunto da União Europeia (18 países) - os valores apresentados pelas elites, pelo operariado e pela média da população. Ora bem, só há uma conclusão a tirar, em nível de cada país ou em nível europeu: com raríssimas excepções à escala nacional e europeia, seja qual for 0 indicador em causa, as elites não só recorrem muito mais às oportunidades de participação política do que o operariado, como se identificam muito mais com os partidos, a classe política e as instituições dos respectivos países; consequentemente, a sua satisfação com a democracia é muito maior do que a da classe operária. Por outras palavras, esses resultados configuram uma virtual confiscação dos sistemas partidários e da própria democracia pelas elites da União Europeia em detrimento das classes subalternas.

A única excepção relevante é o índice designado por responsiveness, que mede a capacidade de iniciativa dos indivíduos e a resposta do sistema à acção colectiva ou individual dos cidadãos. Por aqui, aproximamo-nos dessa "voz" teorizada por Albert Hirschman. São dois indicadores simples: a probabilidade de os inquiridos se envolverem num protesto contra alguma legislação da qual discordassem e qual seria, segundo eles, a resposta positiva ou negativa do sistema perante as iniciativas tomadas pelas pessoas. A probabilidade de tomarem alguma iniciativa não é grande, mas o que faz baixar o índice é o efeito de feedback negativo que tem, para a mobilização dos cidadãos, a expectativa que estes têm de as suas iniciativas "não servirem para nada".

Ora, se, em Portugal e Espanha, as elites tendem a tomar mais iniciativas de protesto do que o operariado, não é esse o caso nos outros países nem no conjunto da União Europeia. Comprova-se, assim, que prevalece, na Península Ibérica, uma relação negativa entre uma elite que procura dissuadir o protesto e, por outro lado, uma classe operária que, perante as estratégias dissuasórias das elites, renuncia por antecipação a fazer ouvir a sua voz, criando, assim, um círculo vicioso. Inversamente, a verificação de que a iniciativa "serve para alguma 


\begin{tabular}{|c|c|c|c|c|c|c|c|c|c|c|c|c|}
\hline \multirow{3}{*}{ 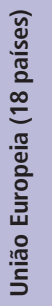 } & $\frac{\infty}{\dot{山}} \underset{\Sigma}{\Sigma}$ & $\begin{array}{l}\stackrel{\infty}{\infty} \\
\stackrel{\infty}{\leftarrow}\end{array}$ & $\frac{\infty}{n^{n}}$ & $\underset{m}{\stackrel{8}{e}}$ & $\stackrel{\infty}{\sim}$ & $\stackrel{\infty}{\infty}$ & $\stackrel{\Re}{\stackrel{n}{\sim}}$ & $\stackrel{+}{\sim}$ & 곡 & 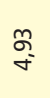 & $\underset{\widetilde{\sigma}}{\tilde{\sigma}}$ & $\stackrel{\Xi}{=}$ \\
\hline & ঃ & $\underset{\widetilde{N}}{\sim}$ & $\stackrel{\substack{\infty \\
\sim}}{\sim}$ & $\frac{\bar{m}}{m}$ & $\frac{9}{i}$ & $\underset{\sim}{\stackrel{\sim}{*}}$ & $\stackrel{\leftrightarrow}{-}$ & 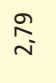 & 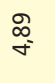 & $\stackrel{\infty}{\stackrel{\infty}{\sim}}$ & $\frac{\sigma}{0}$ & 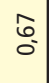 \\
\hline & $\vec{\Psi}$ & ָิ & 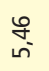 & $\stackrel{\circ}{\stackrel{一}{m}}$ & $\underset{\sim}{\stackrel{0}{N}}$ & $\frac{\bar{n}}{m}$ & $\stackrel{\infty}{-}$ & $\stackrel{\llcorner\infty}{\sim}$ & 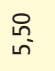 & ๙ุ & $\stackrel{\tilde{m}}{\tilde{o}_{0}}$ & $\stackrel{\stackrel{n}{\leftrightarrow}}{\sim}$ \\
\hline \multirow{3}{*}{ 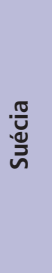 } & $\sum$ & 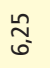 & $\begin{array}{l}\text { \& } \\
\text { เn }\end{array}$ & $\underset{\leftarrow}{\mathbb{f}}$ & $\underset{i}{\stackrel{0}{i}}$ & $\underset{m}{\stackrel{\Xi}{m}}$ & $\stackrel{\Re}{\stackrel{n}{\sim}}$ & $\stackrel{\text { @ }}{\sim}$ & $\frac{1}{6}$ & $\begin{array}{l}\infty \\
\stackrel{\infty}{\infty}\end{array}$ & ণิ & $\stackrel{\infty}{=}$ \\
\hline & о & 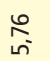 & 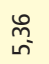 & $\stackrel{g}{;}$ & 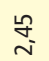 & $\stackrel{+}{\sim}$ & $\stackrel{\sim}{\sim}$ & 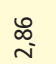 & స్ & $\underset{\forall}{\check{f}}$ & $\underset{\substack{m \\
0}}{\stackrel{m}{0}}$ & $\stackrel{\underset{m}{m}}{\sim}$ \\
\hline & $\vec{w}$ & 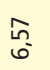 & $\underset{\tilde{\sigma}}{\bar{\sigma}}$ & $\frac{n}{n}$ & $\stackrel{\infty}{\sim}$ & $\underset{m}{\bar{m}}$ & $\underset{f}{\ddagger}$ & $\stackrel{n}{\text { 品 }}$ & 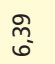 & $\underset{\sim}{\stackrel{\infty}{\sim}}$ & 웡 & 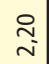 \\
\hline \multirow{3}{*}{ 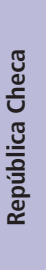 } & $z$ & $\underset{f}{\stackrel{f}{\lessgtr}}$ & $\underset{\sim}{\stackrel{\sim}{*}}$ & $\underset{m}{\underset{n}{\mathbb{N}}}$ & $\underset{\sim}{\stackrel{N}{N}}$ & $\underset{\sim}{\stackrel{N}{N}}$ & $\stackrel{\underset{\sim}{\sigma}}{-}$ & $\stackrel{\infty}{\stackrel{\infty}{N}}$ & 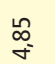 & 年 & 1 & ৪ \\
\hline & о & $\stackrel{\text { L̊ }}{\stackrel{\leftrightarrow}{\circ}}$ & $\underset{\sim}{\bar{f}}$ & $\underset{\sim}{\stackrel{S}{S}}$ & 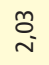 & 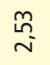 & $\stackrel{\infty}{-}$ & $\stackrel{\substack{n \\
\sim}}{ }$ & $\underset{\sim}{\tilde{\sigma}}$ & ঃุ & 1 & $\stackrel{\Xi}{\circ}$ \\
\hline & $\vec{\Psi}$ & $\begin{array}{l}\stackrel{\infty}{\infty} \\
\stackrel{+}{*}\end{array}$ & 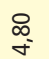 & $\underset{m}{\stackrel{B}{m}}$ & $\underset{\sim}{\stackrel{j}{j}}$ & $\stackrel{m}{\stackrel{m}{m}}$ & $\stackrel{n}{\sim}$ & $\stackrel{\substack{\infty \\
\sim}}{\sim}$ & 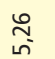 & o. & 1 & $\underset{\sim}{\approx}$ \\
\hline \multirow{3}{*}{ 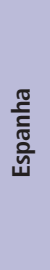 } & $\underset{\Sigma}{z}$ & $\underset{\substack{\infty \\
\sim}}{\stackrel{f}{*}}$ & 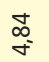 & 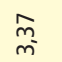 & $\stackrel{\infty}{\sim}$ & $\underset{\sim}{\mathbb{d}}$ & $\stackrel{n}{\stackrel{n}{\sim}}$ & 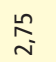 & $\underset{\text { in }}{\stackrel{8}{n^{2}}}$ & $\underset{F}{\mp}$ & $\frac{m}{0}$ & ஜू \\
\hline & ๐ & $\underset{f}{\check{f}}$ & $\underset{\leftarrow}{\bar{\sigma}}$ & 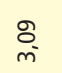 & $\stackrel{\varrho}{=}$ & $\stackrel{\infty}{\sim}$ & $\stackrel{\text { g }}{-}$ & $\underset{\sim}{\stackrel{R}{N}}$ & ֶ̊ & $\stackrel{m}{\sigma}$ & 웅 & $\underset{0}{\mathbb{O}}$ \\
\hline & $\vec{\omega}$ & $\underset{\text { స్ }}{\bar{n}}$ & $\begin{array}{l}\text { L̊ } \\
\text { Ln }\end{array}$ & 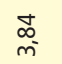 & $\underset{\sim}{\stackrel{N}{N}}$ & $\frac{\bar{m}}{m}$ & 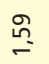 & $\stackrel{\stackrel{n}{\infty}}{\sim}$ & $\underset{\substack{\infty \\
i n}}{\infty}$ & 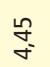 & $\underset{\mathscr{n}}{\stackrel{n}{0}}$ & $\stackrel{+}{\stackrel{\leftrightarrow}{\sigma}}$ \\
\hline \multirow{3}{*}{ 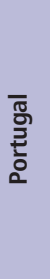 } & $\sum_{\Sigma}^{z}$ & $\stackrel{\text { \& }}{\&}$ & $\underset{\substack{\infty \\
\sim}}{\sim}$ & $\stackrel{\infty}{\sim}$ & $\underset{\sim}{\stackrel{N}{N}}$ & $\underset{i}{i}$ & $\underset{q}{\stackrel{q}{*}}$ & $\underset{\sim}{\stackrel{N}{N}}$ & $\begin{array}{l}\stackrel{\leftrightarrow}{\leftrightarrow} \\
\stackrel{\sigma}{*}\end{array}$ & 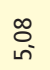 & : & $\begin{array}{l}\bar{\sigma} \\
0\end{array}$ \\
\hline & о & 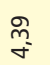 & $\underset{\sim}{\sigma}$ & $\stackrel{i n}{\sim}$ & $\stackrel{\circ}{-}$ & $\underset{\sim}{\stackrel{f}{\sim}}$ & $\stackrel{\hat{m}}{=}$ & $\underset{i}{i}$ & $\underset{f}{\stackrel{g}{\&}}$ & 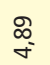 & i̊ & ণ্ \\
\hline & $\vec{w}$ & 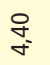 & 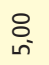 & $\frac{6}{m}$ & $\stackrel{\infty}{\stackrel{\infty}{N}}$ & $\underset{m}{\stackrel{\sim}{m}}$ & $\stackrel{\sim}{\tilde{n}}$ & $\stackrel{\bar{\infty}}{\sim}$ & ָू & $\frac{\infty}{n}$ & $\frac{1}{0}$ & $\begin{array}{l}\bar{\infty} \\
\infty \\
0\end{array}$ \\
\hline & & 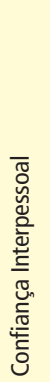 & 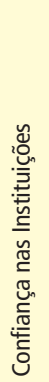 & 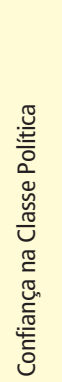 & 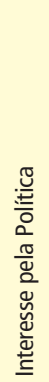 & 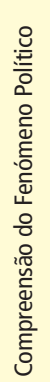 & 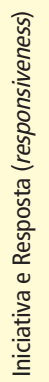 & 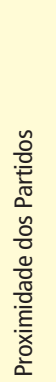 & 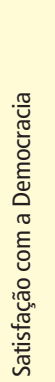 & 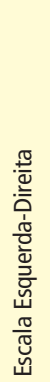 & 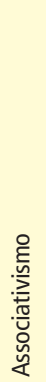 & 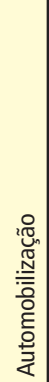 \\
\hline
\end{tabular}


coisa" pode gerar um círculo virtuoso. 0 oposto da "voz" é a "saída", bem exemplificada na história de um país, como Portugal, pela emigração ("votar com os pés")!

Finalmente, se é certo que, na generalidade dos países da União Europeia, as elites, devido à abundância dos seus capitais humano e social, exercitam muito mais plenamente os direitos constitucionais do que o resto da população, esses resultados mostram que, em Portugal, as próprias elites tendem a exercer esses direitos menos do que o operariado de países como a Suécia, por exemplo, e por vezes menos do que a média europeia. Portanto, além do efeito de classe, existe um efeito societal, segundo o qual uma sociedade, como a portuguesa, sofre, no seu conjunto, de um défice tal no nível do exercício da cidadania que as próprias elites revelam, frequentemente, possuir menos capital social do que o conjunto da população europeia.

Em Portugal, efectivamente, os índices de associativismo e de automobilização das elites estão abaixo dos da classe operária sueca. Comparativamente, Portugal sofre, pois, de um défice societal de mobilização. Pode, pois, dizer-se que a capacidade de automobilização ser definidora de uma elite, porventura uma elite alternativa, como se verá a seguir no Quadro 2. É isso que se depreende desse outro quadro

Quadro 2 - Associativismo e automobilização - Portugal (2004)

\begin{tabular}{|l|c|c|}
\hline \multicolumn{2}{|c|}{ (Regressão Linear Múltipla) } \\
\hline Interesse pela política & Associativismo & Auto-mobilização \\
\hline Mobilização cognitiva & - & - \\
Iniciativa e resposta política & - & $0.141^{* * *}$ \\
Exposição aos media noticiosos & $0.144^{* * *}$ & $0.112^{* * *}$ \\
Confiança interpessoal & $0.155^{* * *}$ & $0.132^{* * *}$ \\
Classe social & - & - \\
Classe social subjectiva & $0.078^{*}$ & $-110^{* * *}$ \\
Escolaridade & - & - \\
Rendimento & - & $0.082^{*}$ \\
Sexo & $0.135^{* *}$ & $0.055^{*}$ \\
Idade & $-0.065^{*}$ & $-0.083^{*}$ \\
Prática religiosa & $0.111^{* *}$ & - \\
Socialização primária & $0.182^{* * *}$ & - \\
Socialização secundária & - & $0.217^{* * *}$ \\
Efeito-metropolitano & $0.220^{* * *}$ & $0.081^{* *}$ \\
Posição política (esquerda vs. Direita) & - & - \\
Variância explicada (Adjusted $R 2$ ) & $-0.103^{* * *}$ & $48.5 \%$ \\
$N$ (Minimum) & $21,4 \%$ & 1152 \\
\hline
\end{tabular}

Nota: Os valores são coeficientes de regressão estandardizados (betas) estatisticamente significativos: ${ }^{*} p<0,05 ;{ }^{* *} p<0,01 ;{ }^{* * *} p<0,001$. As células vazias correspondem a coeficientes de regressão estandardizados estatisticamente não significativos $(p>0,01)$. 
produzido no contexto de uma nova pesquisa sobre as modalidades de exercício da cidadania (Cabral e Carreira da Silva, 2007). Perante esses resultados, é lícito perguntar se não estaremos diante de uma mudança cultural, um shift correlativo daquela outra mudança, identificada há duas décadas por Ronald Inglehart, dos valores e atitudes materialistas em direcção àquilo a que ele chamou então "pós-materialismo" (Inglehart, 1990). Agora, porém, tratar-se-ia de um shift, não tanto no nível dos conteúdos como, sobretudo, no nível das formas de exercer a cidadania e de desafiar as elites instaladas, seja no poder, seja nas próprias instâncias de contrapoder (Cabral, 2009). ${ }^{4}$

Identificámos, assim, duas modalidades distintas de exercício cidadão: por um lado, o associativismo clássico, ou seja, a pertença a associações cívicas, culturais, desportivas, partidos, sindicatos, ordens profissionais, etc., em suma, o associativismo associado ao típico capital social identificado por Putnam, em qualquer das suas vertentes, aberta (bridging) ou fechada (bonding); por outro lado, formas novas daquilo a que chamo automobilização: tipicamente, um cidadão é membro de um partido e figura, portanto, na coluna do associativismo; quando esse partido convoca uma acção, o cidadão é livre de responder ou não à convocatória, isto é, tem de fazer um esforço suplementar no sentido de estar presente, fazendo, assim, ouvir a sua voz; é este último passo pessoal que designo por automobilização.

Ora bem, há indicadores sociodemográficos de sinal estatístico contrário. Dois são particularmente interessantes, pois apontam para a mudança sociocultural. Trata-se do género e da idade. As mulheres estavam então menos presentes no associativismo clássico e mais ligadas a novas formas da automobilização, porventura mais soltas e até erráticas, com menos compromissos no tempo, mas maior empenhamento no momento, digamos assim; os homens, em contrapartida, estavam mais associados ao capital social convencional, mas com menor saliência na automobilização. Quanto à idade, passa-se algo de análogo: o associativismo convencional é uma forma de exercício cidadão de pessoas mais velhas, enquanto os jovens se salientam entre quem se orienta preferencialmente para as modalidades de automobilização. 0 sentido da mudança em favor destas últimas modalidades é indicado, precisamente, pela juventude dos seus aderentes.

Vale a pena acrescentar que não há necessariamente contradição entre as duas modalidades; elas não se excluem mutuamente, antes, pelo contrário, reforçam-se uma à outra. Verifica-se, contudo, que, se há sobreposição entre elas, como acontece em $40 \%$ a $50 \%$ dos casos, a automobilização é mais geradora de associativismo do que este é gerador de mobilização. Por outras palavras, é mais provável que o envolvimento numa rede aberta de protesto leve à criação de uma associação ou à adesão a uma organização previamente constituída do que a pertença a uma dessas associações - hierarquizadas e com objectivos já estabelecidos - leve à participação activa. Acresce, por último, que a modalidade da automobilização é de longe aquela que melhor adere $(48,5 \%$ de "variância explicada") ao modelo do exercício activo da cidadania política (em Portugal como em alguns outros países, a "variância explicada" pelo associativismo é menos de metade: $21,4 \%$ ). 
0 carácter inovador dessa mudança cultural evolução decorre, precisamente, do facto de essas lideranças serem jovens e femininas, não só em Portugal como na maior parte dos países europeus e no Canadá. Essas novas elites são, pois, menos dependentes das modalidades convencionais do capital social clássico e mais ligadas - por isso falamos, a propósito delas, de "linking social capital", capital social de ligação $0^{5}$ - a formas de expressão de uma sociedade civil em rede, menos corporativa e menos mercantil do que tem sido no passado nas democracias ocidentais. Em suma, para retomar os termos de Hirschman, jovens elites emergentes que recusaram a abandonar a liça (exit) e que, ao exercício mais ou menos passivo da lealdade às instituições e interesses estabelecidos (loyalty), preferem fazer ouvir a sua voz (voice).

\section{Concluindo}

Com efeito, desde que a teoria da cultura cívica começou a ser testada empiricamente, a "estrutura de inferência" adoptada por Almond e Verba (1963) foi contestada, não só devido ao papel negligenciável atribuído por eles aos atributos sociodemográficos da população, como, sobretudo, à exclusiva preocupação dos autores com a estabilidade da democracia. Isso levou-os a desprezar a questão da qualidade dos regimes concretos e a atribuir a responsabilidade pelo mau funcionamento das instituições a culturas cívicas de massa alegadamente inadequadas à democracia, em vez de admitir a existência de efeitos de retroacção negativa do comportamento das elites sobre o dos cidadãos (Pateman, 1980). Em sociedades como a portuguesa, essa retroacção contribui certamente para a falta generalizada de confiança social e de mobilização política (Cabral, 2003).

Algo de análogo sucede com a teoria do capital social, cujas reconhecidas dificuldades de operacionalização se devem em parte às próprias indefinições conceptuais. Não só o bom funcionamento das instituições democráticas é considerado dependente do stock de capital social, como tão depressa se diz que é o desenvolvimento das redes de acção colectiva que gera a confiança interpessoal e institucional, como também se afirma que, sem confiança prévia, não é possível estabelecer os laços de cooperação que constituem o capital social (Fukuyama, 1995), conforme o próprio Putnam também admitirá no seu Bowling alone. Não é, pois, de surpreender que Kenneth Newton tenha concluído que as relações entre confiança e redes sociais são "um problema da galinha e do ovo" (Newton, 1999).Assim, o exercício pleno da cidadania política (participação associada e automobilização), bem como da própria participação social (voluntariado), encontra-se no termo de uma cadeia de efeitos compostos que se inicia com os atributos sociodemográficos dos cidadãos e ao longo da qual é possível identificar um conjunto de mediações relevantes, tais como: (1) a confiança social e política; (2) a compreensão do fenómeno político e o sentimento de eficácia pessoal; (3) o interesse pela vida política, a mobilização cognitiva e a exposição aos media informativos; (4) finalmente, a adequação entre a oferta partidária e a procura de bens políticos (Elster, 1985), ou seja, o sentimento dos cidadãos de serem 
bem-representados como teste ao bom funcionamento das instituições democráticas. Em Portugal, hoje em dia, o primeiro desses testes (negativo) é a elevada abstenção eleitoral que pode chegar a $50 \%$ ou mais conforme as eleições. Começa por aí o défice democrático!

\section{[I] https://orcid.org/0000-0003-4679-5569}

Universidade de Lisboa, Instituto de Ciências Sociais. Lisboa, Portugal. mvcabral@ics.ulisboa.pt

\section{Notas}

(1) Em particular, o capítulo final: "Concluding notes on social philosophy".

(2) Wacquant (1998) e Silkoset, R. Destructive Social Capital. Disponível em: http://www.suffolk.edu/ files/Sawyer_MOPAN/silkoset_desctructive_social_capital.pdf. Aesso em: jun 2018.

(3) Hirschman (1970).

(4) Ver também. Welzel; Inglehart; Deutsch (2005).

(5) Por ex.: https://wagner.nyu.edu/files/faculty/publications/Br_J_Soc_Work-2010-Hawkins-1777-93. pdf. Acesso em: jun 2018.

\section{Referências}

ALEXANDER, J. (ed.) (1998). Real Civil Societies: dilemmas of institutionalization. Londres, International Sociological Association.

ALMOND, G. e VERBA, S. (eds). (1963). The civic culture: political attitudes and democracy in five nations. Boston/MA, Little Brown.

CABRAL, M. V. (1997). Cidadania política e equidade social. Oeiras, Celta.

(2000). "O exercício da cidadania política em Portugal". In: CABRAL, M. V.; VALA, J. e FREIRE, J. (orgs.). Trabalho e cidadania. Lisboa, Imprensa de Ciências Sociais, pp. 123-162.

(2003). O exercício da cidadania política em perspectiva histórica (Portugal e Brasil). Revista Brasileira de Ciências Sociais, v. 51, pp. 31-60. 
CABRAL, M. V. (2006). Class effects and societal effects: Elite and working class attitudes towards political citizenship from a European comparative perspective. Portuguese Journal of Social Science, v. 5, n. 3, pp. 159-178.

(2008a). "Efeito metropolitano e cultura política: novas modalidades de exercício da cidadania na metrópole de Lisboa". In: CABRAL, M. V.; SILVA F. C. da e SARAIVA, T. (orgs.). Cidade \& Cidadania: governança urbana e participação cidadã. Lisboa, Imprensa de Ciências Sociais.

(org.) (2008b). Sucesso e insucesso: escola, economia, sociedade. Lisboa, Fundação Calouste Gulbenkian.

(2009). Civic and political participation: a new culture shift? - evidence from 12 countries. In: THE 21ST IPSA WORLD CONGRESS. Santiago de Chile.

CABRAL, M. V. e CARREIRA DA SILVA, F. (2007). "Ciudad y ciudadanía en Portugal. El 'efectometrópolis'sobre el ejercício de la ciudadanía política”. In: CLARK, T. N. e NAVARRO, C. J. (eds). La nueva cultura política. Tendencias globales y casos iberoamericanos. Madrid e Buenos Aires, Miño y Dávila.

CASTEL, R. (1995). Les métamorphoses de la question sociale: une chronique du salariat. Paris, Librairie Fayard.

COLEMAN, J. S. (1990). Foundations of social theory. Harvard, Harvard University Press.

ELSTER, J. (1985). "The market and the forum: three varieties of political theory". In: ELSTER, J. e HYLAND. A. (eds.). Foundations of social choice.

ESPING-ANDERSEN, G. (1990). The three worlds of welfare capitalism. Cambridge, Polity Press.

FREIRE, J. (2008). "Evoluções sociais no campo do associativismo". In: CABRAL, M. V. (org.). Sucesso e insucesso: escola, economia, sociedade. Lisboa, Fundação Calouste Gulbenkian.

FUKUYAMA, F. (1995). Trust. The social virtues and the creation of prosperity. Londres, Penguin Books.

HIRSCHMAN, A. (1970). Exit, voice and loyalty. Harvard, Harvard University Press.

INGLEHART, R. (1990). Culture shift in advanced industrial society. Princeton, N. J., Princeton University Press.

KEYNES, J. M. (1936). General theory of employment, interest and money.

LIJPHART, A. (1980). "The structure of inference". In: ALMOND, G.; VERBA, S. (eds.). The Civic Culture Revisited. Boston/Toronto, Little Brown.

MARSHALL, T. H. (1992). Citizenship and social class. Londres, Pluto Press.

NEWTON, K. (1999). "Social capital and democracy in Europe". In: van DETH, J. W. et al. (orgs.). Social capital and European Democracy. Londres, Routledge.

PATEMAN, C. (1980). "The civic culture: a philosophic critique". In: ALMOND, G. e VERBA, S. (eds.). The Civic Culture Revisited. Boston, Little Brown.

PUTNAM, R. (1993). Making democracy work: civic traditions in modern Italy. Princeton, N. J., Princeton University Press.

(2003). Bowling alone: The collapse and revival of American community. Nova York, Simon \& Schuster. 
RAWLS, J. (1972). A Theory of Justice. Cambridge, Harvard University Press, Mass.

SALAMON, L. M. et al. (1999-2004). Global civil society: dimensions of the non-profit sector. The Johns Hopkins Center for Civil Society Studies.

SEN, A. K. (1983). Poor, relatively speaking. Oxford Economic Papers, v. 35, n. 2, pp. 153-169.

SILKOSET, R. (2008). Destructive Social Capital . Disponível em: http://www.suffolk.edu/files/Sawyer_ MOPAN/silkoset_desctructive_social_capital.pdf. Acesso em: set 2018.

WACQUANT, L. (1998). “Negative social capital: state breakdown and social destitution in America's urban core". Netherlands Journal of Housing and the Built Environment, v. 13, n. 1. Acesso em: jun 2018.

WEBER, M. (1958 [1921]). The city. Nova York, The Free Press.

WELZEL C.; INGLEHART, R. e DEUTSCH, F. (2005). Social Capital, Voluntary Associations and Collective Action: Which Aspects of Social Capital Have the Greatest "Civic" Payoff? Journal of Civil Society, v. 1 , n. 2, pp. 121-146.

Texto recebido em $20 /$ jul/2018

Texto aprovado em 17/set/2018 
